\title{
Thyroglobulin Gene Mutations in Congenital Hypothyroidism
}

\author{
Héctor M. Targovnik Cintia E. Citterio Carina M. Rivolta \\ Laboratorio de Biología Molecular, Cátedra de Genética y Biología Molecular, Facultad de Farmacia y Bioquímica, \\ Universidad de Buenos Aires, Buenos Aires, Argentina
}

\section{Key Words}

Congenital hypothyroidism $\cdot$ Fetal goiter .

Dysembryogenesis $\cdot$ Thyroglobulin gene $\cdot$ Mutation

\begin{abstract}
Human thyroglobulin (TG) gene is a single copy gene, $270 \mathrm{~kb}$ long, that maps on chromosome 8q24.2-8q24.3 and contains an $8.5-\mathrm{kb}$ coding sequence divided into 48 exons. TG is exclusively synthesized in the thyroid gland and represents a highly specialized homodimeric glycoprotein for thyroid hormone biosynthesis. Mutations in the TG gene lead to permanent congenital hypothyroidism. The presence of low TG level and also normal perchlorate discharge test in a goitrous individual suggest a TG gene defect. Until now, 52 mutations have been identified and characterized in the human TG gene with functional impact such as structural changes in the protein that alter the normal protein folding, assembly and biosynthesis of thyroid hormones. 11 of the mutations affect splicing sites, 11 produce premature stop codons, 23 lead to amino acid changes, 6 deletions ( 5 single and 1 involving a large number of nucleotides) and 1 single nucleotide insertion. TG mutations are inherited in an autosomal recessive manner and affected individuals are either homozygous or compound heterozygous. The p.R277X, p.C1058R,
\end{abstract}

p.C1977S, p.R1511X, p.A2215D and p.R2223H mutations are the most frequently identified TG mutations. This mini-review focuses on genetic and clinical aspects of TG gene defects.

Copyright $\odot 2011$ S. Karger AG, Basel

\section{Introduction}

Congenital hypothyroidism $(\mathrm{CH})$ is the most frequent endocrine disease in infants, with a prevalence of $1: 2,000-1: 4,000$ in newborns $[1,2]$. It is also one of the most common preventable causes of cognitive and motor deficits. $\mathrm{CH}$ occurs when infants are unable to produce sufficient amounts of thyroid hormone at birth.

Pathophysiological classification based on the genotype/phenotype analysis divides $\mathrm{CH}$ into two main categories: (i) caused by disorders of thyroid gland differentiation, migration or growth (thyroid dysgenesis (TD) and resistance of thyrotropin (TSH)), which accounts for $85 \%$ of cases, or (ii) by defects in any step of thyroid hormone synthesis (dyshormonogenesis), which accounts for the remaining $15 \%$ of cases [1, 2] (fig. 1). The TD group includes heterogeneous diseases (sporadic 98\%, familial 2\%) resulting from thyroid gland agenesis or athyreosis, ectopic thy-

\section{KARGER}

Fax +4161306 1234

E-Mail karger@karger.ch

www.karger.com
(C) 2011 S. Karger AG, Basel

1663-2818/11/0755-0311\$38.00/0

Accessible online at:

www.karger.com/hrp
Dr. Héctor M. Targovnik

Laboratorio de Biología Molecular, Cátedra de Genética y Biología Molecular

Facultad de Farmacia y Bioquímica, Universidad de Buenos Aires

Junín 956, 1113 Buenos Aires (Argentina)

Tel. +54 114964 8296, E-Mail htargovn@ffyb.uba.ar 


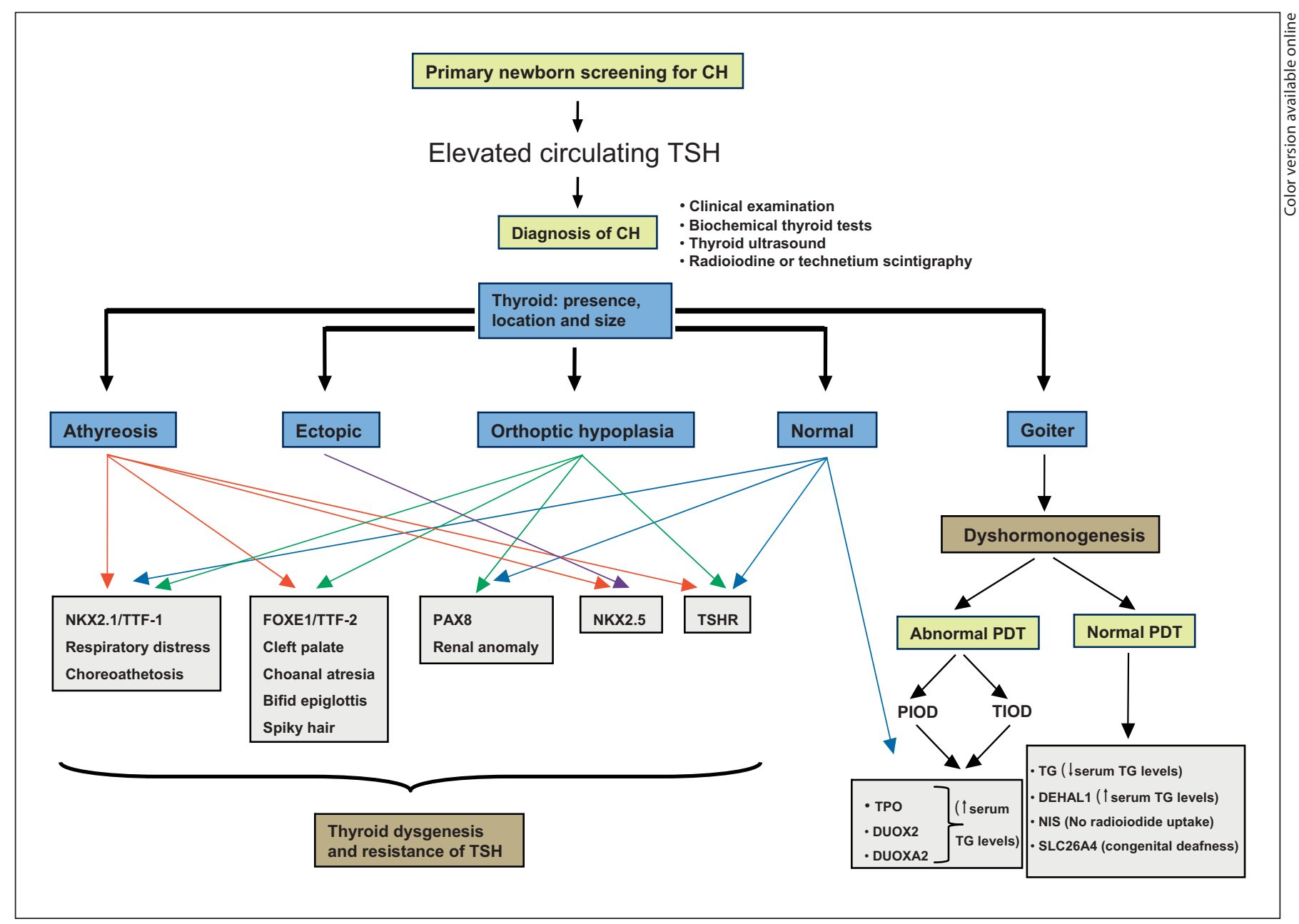

Fig. 1. Algorithm for investigating the molecular genetic basis of congenital hypothyroidism $(\mathrm{CH})$. PDT $=$ Perchlorate discharge test (radioiodine discharge within $30 \mathrm{~min}$ after $\mathrm{ClO}_{4}$ administration); $\mathrm{PIOD}=$ partial iodide organification defect (PDT $<90 \%) ;$ TIOD = total iodide organification defect $($ PDT $>90 \%)$; NKX2.1 = also known as TTF-1, TITF1, or T/EBP; FOXE1 = also known as TTF-2, TITF2 or FKHL15; PAX-8 = paired box transcription factor 8 ; TSH $=$ thyrotropin; TSHR = receptor for TSH;

roid tissue at the base of the tongue, or in any position along the thyroglossal tract and orthoptic hypoplastic thyroid gland $[1,2]$. In $5 \%$ of these patients, the $\mathrm{CH}$ is associated with mutations in the NKX2.1 (also known as TTF-1, TITF1 or T/EBP), FOXE1 (also known as TTF-2, TITF2 or FKHL15), PAX-8, NKX2.5 and TSH receptor (TSHR) genes $[1,2]$. A normal-sized thyroid gland may be due to heterozygous loss of function mutations of the TSHR, while homozygous TSHR mutations cause $\mathrm{CH}$ with hypoplastic gland. Dyshormonogenesis is an autosomal recessive disorder that results in a bilobed thyroid located in the
NIS = sodium iodide symporter; SLC26A4 = gene encoding pendrin (also known as PDS, Pendred syndrome), a multifunctional anion exchanger; DEHAL1 = iodotyrosine deiodinase; TG = thyroglobulin; TPO = thyroperoxidase; DUOX2 = dual oxidase 2; DUOXA 2 = dual oxidase maturation factor A2. The extrathyroid malformations for NKX2.1, FOXE1 and PAX8 mutations are indicated. cervical position that is increased in size (goiter) by the trophic role of the elevated TSH levels, in response to reduced thyroid hormone levels Dyshormonogenesis has been linked to mutations in the sodium iodide symporter (NIS) [3], SLC26A4 (which encodes pendrin, a multifunctional anion exchanger) [4], thyroperoxidase (TPO) [5], dual oxidase 2 (DUOX2) [6], DUOX maturation factor 2 (DUOXA2) [6], dehalogenase 1 (DEHAL1) [7] and thyroglobulin (TG) [8] genes (fig. 1). Interestingly, Cavarzere et al. [9] describe infants with $\mathrm{CH}$ due to iodide organification defects that do not have goiter at birth. 
Primary newborn screening for $\mathrm{CH}$ has been adopted by most countries around the world [1, 2], using either primary $3,5,3^{\prime}, 5^{\prime}$-tetraiodothyronine or thyroxine $\left(\mathrm{T}_{4}\right)$ follow-up TSH or primary TSH testing. In recent years, new testing technology allowed adaptation of precise immunoassays for TSH using a small quantity of blood in special filter paper cards [2]. TSH is high at screening, so the patient is called in to measure 3,5,3'-triiodothyronine $\left(\mathrm{T}_{3}\right), \mathrm{T}_{4}$ and $\mathrm{TSH}$. Early detection and treatment of such infants are critical to normal brain development and physical growth and have been successful as evidenced by near-normal neurocognitive outcome in the majority of infants with $\mathrm{CH}[1,2]$. Consequently, appropriate genetic diagnosis and genetic counseling should be considered in all cases of $\mathrm{CH}$. In neonates a complete diagnosis of $\mathrm{CH}$ should include clinical examination, biochemical thyroid tests, thyroid ultrasound, radioiodine or technetium scintigraphy and perchlorate discharge test (PDT) $[1,2]$ (fig. 1). PDT and the measurement of TG serum concentration represented an important diagnostic tool that helps to differentiate patients with iodide organification disorder of those with DEHAL1 or TG deficiencies (fig. 1). In cases of thyroid agenesis, serum TG levels are absent. It is important to note that the management of all phenotypic forms of $\mathrm{CH}$ is the same for the clinician, without knowing the exact genetic cause and it is based on rapidly restoring thyroid function to normal range by thyroid hormone replacement.

TG is the most abundant expressed protein in the thyroid gland. The intrathyroidal metabolism of this protein is dependent on its traffic and secretion to the apical extracellular follicular lumen, where it plays an essential role in the process of thyroid hormone synthesis [8].

Genetic defect in TG synthesis and secretion are associated with congenital goiter [8] and endemic or non-endemic simple goiter [10-12]. There are cases of thyroid carcinoma developing from dyshormonogenic goiters with TG mutations [13-15]. The TG gene has been also identified as the major susceptibility gene for familial autoimmune thyroid disease [16].

Since the first description of TG mutations in patients with $\mathrm{CH}$ in 1991 [17], 52 different mutations have been reported [8]. Some mutations have been also identified in animal models, resulting in aberrant TG protein expression [18-22]. The study of mutations in TG and their molecular mechanisms may be useful for further understanding of the structural and functional aspects of the mutant protein, the correlation between genotype and phenotype, and can aid in genetic counseling regarding recurrence risk within the family.

Thyroglobulin Gene Mutations in Congenital Hypothyroidism
The present mini-review provides a summary and critical analysis of the mutational process that leads to primary $\mathrm{CH}$ with defective $\mathrm{TG}$, its pathophysiological role and the clinical relevance of the defects.

\section{TG Gene, mRNA and Protein}

TG, a homodimeric glycoprotein of $660 \mathrm{kDa}$, is synthesized exclusively in the thyroid gland and represents a highly specialized matrix for thyroid hormone biosynthesis [8]. The molecular analysis of TG began in 1985 when the full-length transcript encoding bovine TG was reported [23]. Subsequently, the human cDNA and its corresponding gene have been isolated and widely characterized [24-29]. The TG gene is organized in 48 exons, spanning over $270 \mathrm{~kb}$ on human chromosome 8q24.2$8 \mathrm{q} 24.3$ [24-29]. TG gene expression is stimulated by thyrotrophin (TSH) through the modulation of the intracellular level of cyclic adenosine monophosphate (cAMP) via its receptor (TSHR) located at the basal membrane of the cell [8]. Transcription of the TG gene is under control of TTF-1, TTF- 2 and PAX- 8 by binding of these factors to the TG promoter on their consensus sequences [8].

The human TG mRNA is $8.5 \mathrm{~kb}$ long $[25,29]$. The general organization of the sequence showed a 41-nucleotide 5 '-untranslated segment, followed by a single open reading frame of 8,307 bases and a 3'-untranslated segment ranging from 101 up to $120 \mathrm{bp}[25,29]$. The pre-protein monomer is composed of a 19 -amino-acid signal peptide followed by a 2,749-residue polypeptide [25, 29]. 21 SNPs were identified and characterized in the coding sequence of the TG gene, 14 of them resulting in amino acid polymorphisms $[29,30]$.

Eighty percent of TG has three repeated regions comprising cysteine-rich repeat domains covalently bound by disulfide bonds (11 type 1, 3 type 2 and 5 type 3 ) [25, 29]; the remaining structure constitutes a carboxyl-terminal domain homologous to acetylcholinesterase (ACHE-homology domain) [25, 29, 31].

Interestingly, type-1 repeats could function as binder and reversible inhibitors of proteases in the lysosomal pathway. TG type-1 domains have been found as part of many proteins with different domain architectures, functions, and phyletic distributions [32]. In total, 170 protein sequences were found containing 333 type-1 modules. Six architecturally distinct groups containing the type-1 domain were identified in vertebrate in addition to the TG group: testicans, secreted modular calcium-binding proteins (SMOCs), Trops, splice variant of the major histo-

Horm Res Paediatr 2011;75:311-321 
compatibility complex class II-associated invariant chain, insulin-like growth factor-binding proteins (IGFBP-1, -2, $-3,-4,-5,-6)$ and nidogen [32].

The ACHE homology domain is essential for normal conformational maturation and intracellular transport of TG to the site of its iodination and hormonogenesis, via the secretory pathway $[33,34]$. Studies showed that the ACHE-like domain may function as an intramolecular chaperone and as a molecular escort for type-1, -2 and -3 TG domains [35].

After translation, intensive post-translational modifications take place in the rough endoplasmic reticulum (RER), Golgi apparatus, apical membrane and follicular lumen and include intrachain disulfide bond formation, glycosylation, sialylation, sulfatation, phosphorylation and iodination $[8,34]$. TG conformational maturation ends in TG homodimerization with progression to a compact ovoid structure and finally correctly folded TG homodimers are secreted as a dimer into the follicular lumen. Several endoplasmic reticulum chaperones, such as calnexin, Grp94 and Bip, interact with TG during its maturation and may serve to prevent export of improperly folded TG proteins by a process known as RER-associated degradation [8].

The central steps in thyroid hormone synthesis take place at the apical membrane of follicular thyroid cells. Once TG has reached the follicular lumen, several tyrosines residues are iodinated $[36,37]$.

The subsequent inter- or intrachain coupling between either two diiodotyrosine residues, or between a diiodotyrosine and a monoiodotyrosine residue, results in the formation of $\mathrm{T}_{4}$ or $\mathrm{T}_{3}$. Four hormonogenic acceptor tyrosines have been identified and localized at positions 5, 1291, 2554 and 2747 in human TG and three tyrosines localized at positions 130, 847 and 1448 have been proposed as donor sites $[36,37]$. The iodination and coupling reactions are mediated by TPO, for which a source of hydrogen peroxide is required [5]. The $\mathrm{H}_{2} \mathrm{O}_{2}$ generation system of the thyroid involves a DUOX system composed of DUOX1, DUOX2, DUOXA1 and DUOXA2 [6]. When TG is endocytosed by thyrocytes and transported to lysosomes, thyroid hormones are released by proteolytic cleavage of TG.

TG interacts with several proteins of the apical membrane in the exocytosis and endocytosis pathways of thyrocytes, such as apical membrane asialoglycoprotein receptor (ASGPR), megalin, low-density lipoprotein receptor-associated protein (RAP) and protein disulfide isomerase (PDI) [8].
The ASGPR transports new synthesized TG to the follicular lumen, whereas megalin, a member of the lowdensity lipoprotein receptor family, mediates the TG transepithelial transport or transcytosis from apical to the basolateral surface of the thyrocyte. RAP is necessary for the folding of megalin and interacts not only with megalin but also with TG [8]. Transcytosis is thought to be one of the mechanisms that account for the presence of intact TG in the circulation. Mature and immature TGs are removed from the follicular lumen. The immature molecules are internalized and recycled through the trans-Golgi compartments. PDI is thought to be the candidate receptor that mediates the internalization [8]. In addition to fluid-phase pinocytosis, the lysosomal pathway for mature TG proteolytic cleavage might be mediated by an affinity receptor, although receptors that mediate this intracellular route are unknown.

\section{TG Mutations and Congenital Hypothyroidism}

Fifty-two mutations have been identified and characterized in the human TG: 11 splice site mutations, 11 nonsense mutations, 23 missense mutations, 6 deletions (5 single and 1 involving a large number of nucleotides) and 1 single nucleotide insertion $[10-15,17,30,38-58]$ (table 1; fig. 2, 3). Because TG mutations are inherited in an autosomal recessive manner, the patients should be homozygous or compound heterozygous for gene mutations and the parents should be carriers of one TG mutation.

The first-described human mutation causing a TG defect was the mutation g.IVS3-3C >G [17]. The p.C1058R and p.C1977S mutations are the most frequently identified TG mutations in Japanese population [30], whereas the frequent mutations p.R277X [41, 44, 45, 48, 49, 53, 55, 57, 58], p.R1511X [38, 44, 46, 49, 56], p.A2215D [48, 52, 53, 55] and p.R2223H $[15,43,55]$ were found in Caucasian population (table 1).

All cases with TG mutations shared a similar phenotype that included lower or absent serum TG, high levels of serum TSH with simultaneous low levels of circulating thyroid hormones and elevated radioiodide or technetium uptake with normal organification of iodide, identified by PDT. Some patients might have normal to high triiodothyronine levels. Abnormal TG synthesis and secretion in patients with $\mathrm{CH}$ may be confirmed by near absence of serum TG elevation 24 and $48 \mathrm{~h}$ after stimulation with recombinant human TSH. All patients had a thyroid ultrasound or ${ }^{99} \mathrm{Tc}$ scan showing a normally located and enlarged thyroid gland. Goiters are usually 
Table 1. Thyroglobulin gene mutations

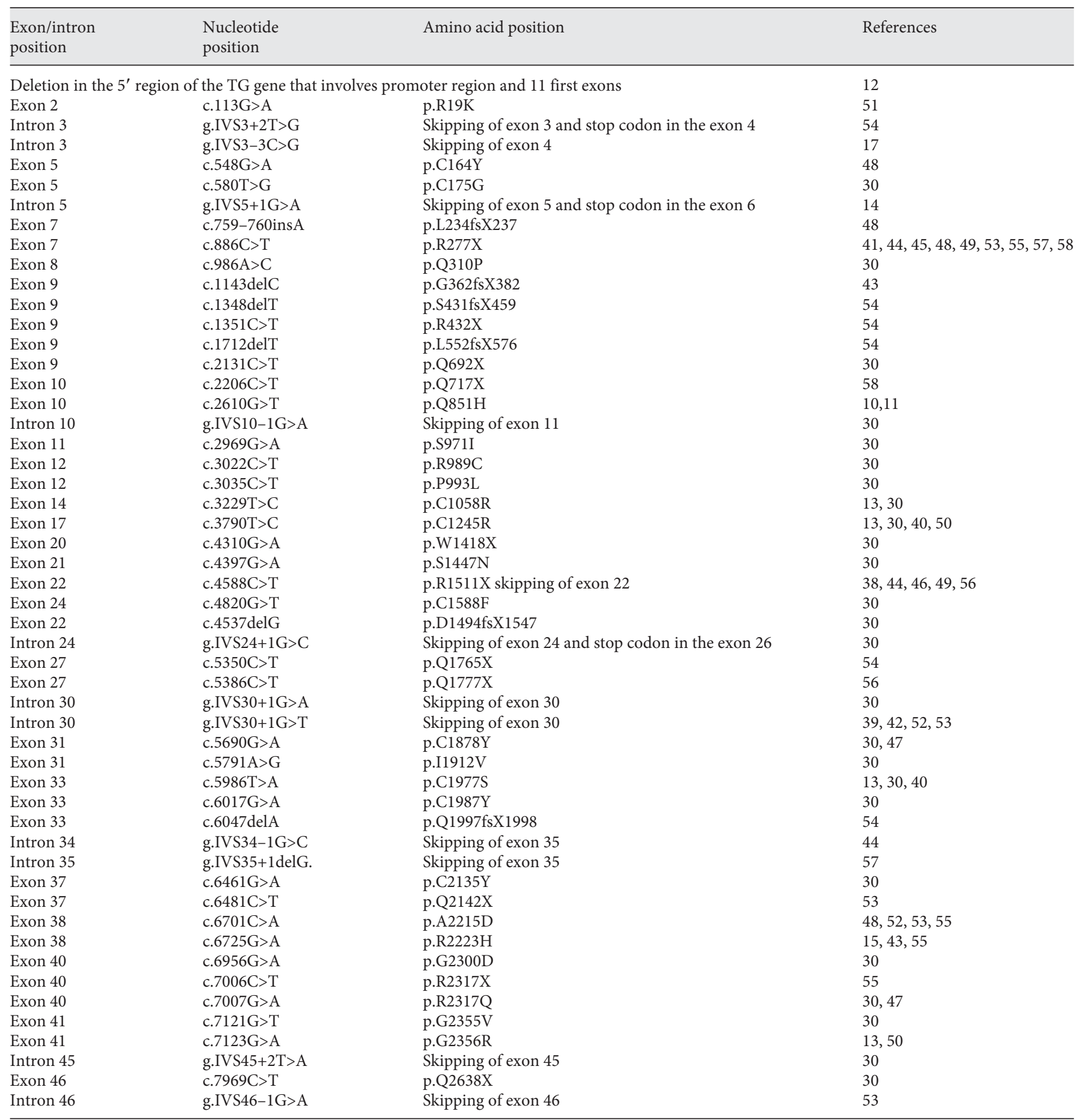

The nucleotide position is designated according to TG mRNA reference sequences (GenBank accession No. NM_ 003235). The A of the ATG of the initiator methionine codon is denoted nucleotide +1 . The amino acid positions are numbered after subtracting the 19 -amino-acid signal peptide. Intronic nucleotides located upstream of the exon have negative numbering, while those located downstream have positive numbering. Frame shifting mutations are designated by ' $f$ ' after a description of the first amino acid affected by the change (insertion or deletion) and followed by ' $\mathrm{X}$ ', that indicates the codon position which the new reading frame ends in a stop. 


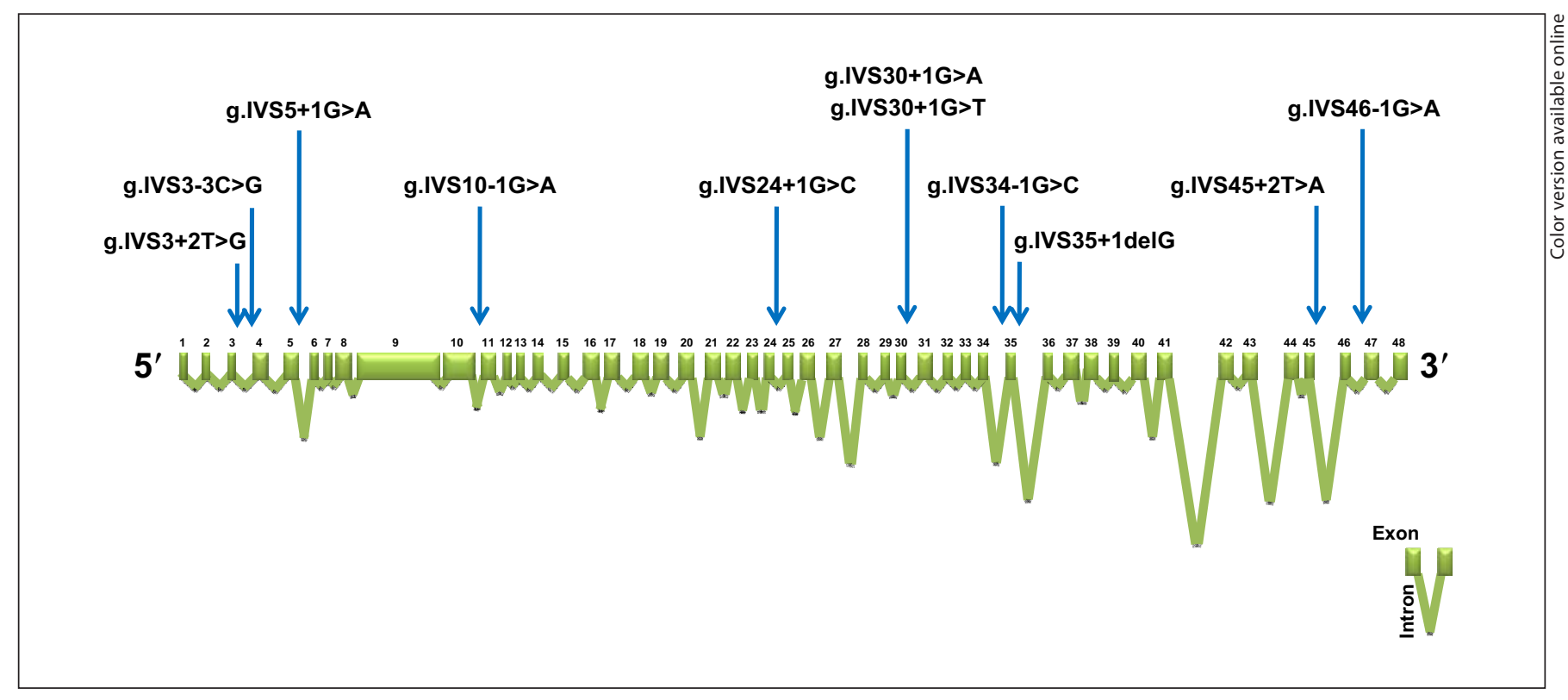

Fig. 2. Intron/exon organization of the TG gene with reference to the positions of the acceptor and donor splice site mutations. Note the difference between scales used for introns and exons. Orientation is given according to the mRNA structure. Intronic nucleotides located upstream of the exon have negative numbering, while those located downstream have positive numbering.

very large and have an elastic and soft consistency. Many of these patients present as adult nodular hyperplasia. The clinical spectrum ranges from moderate to severe hypothyroidism. However, Hishinuma et al. [30] have reported 26 different inactivating mutations in the TG gene in congenital goiter euthyroid or mildly hypothyroid. The very low TG levels are the basis for the selection of patients for molecular studies in the TG gene.

Exon skipping in the TG gene can be caused by single nucleotide substitutions in donor or acceptor splice sites involving the $+1 /+2$ (g.IVS3 $+2 \mathrm{~T}>\mathrm{G}$ [54], g.IVS5 $+1 \mathrm{G}>\mathrm{A}$ [14], g.IVS24+1G $>C$ [30], g.IVS30+1G $>$ A [30], g.IVS30 $+1 G>T$ [39, 42, 52, 53], g.IVS35+1delG [57], g.IVS45 $+2 \mathrm{~T}>\mathrm{A}$ [30]) or $-1 /-3$ position, (g.IVS3-3C $>\mathrm{G}$ [17], g.IVS10-1G>A [30], g.IVS34-1G>C [44], g.IVS46-1G>A [53]), respectively (fig. 2; table 1). The elimination of exons in the TG gene by aberrant splicing results in an altered ability to transfer an iodophenoxyl group from the donor site to the acceptor iodotyrosine in the coupling machinery.

The 11 inactivating mutations that generate a truncated protein have been localized in exons 7 (p.R277X) [41, 44, 45, 48, 49, 53, 55, 57, 58], 9 (p.R432X, p.Q692X) [30], 10 (p.Q717) [58], 20 (p.W1418X) [30], 22 (p.R1511X) [38, 44, 46, 49, 56], 27 (p.Q1765X, p.Q1777X) [54, 56], 37
(p.Q2142X) [53], 40 (p.R2317X) [55] and 46 (p.Q2638X) [30] of the TG gene (fig. 3; table 1).

The p.R277X mutation is the most frequently reported mutation in the TG gene and affected individuals are either homozygous or compound heterozygous mutations $[41,44,45,48,49,53,55,57,58]$. This mutation has been found in families from Brazil, Argentina, Galicia and France $[41,44,45,48,49,53,55,57,58]$. The functional consequences of p.R277X-truncated protein are a complete loss of the central and carboxy-terminal hormonogenic domains (tyrosines localized at positions 1291, 2554 and 2747) and, consequently, limited ability to generate thyroid hormone. However, p.R277X TG peptide retains its ability for $\mathrm{T}_{4}$ synthesis because still harbors both the acceptor tyrosine 5 and the donor tyrosine 130 (fig. 3).

The p.R1511X mutation was identified in members of three unrelated families with a history of congenital goiter

Fig. 3. Structural organization of the wild-type and truncated form of TG proteins due to nonsense mutations in the TG gene. The repetitive units of types 1,2 and 3, and the acetylcholinesterase-homology domain (ACHE-like domain) are represented by boxes. The positions of $\mathrm{T}_{4}\left(5,1291\right.$ and 2747) and $\mathrm{T}_{3}(2554)$ are shown. 


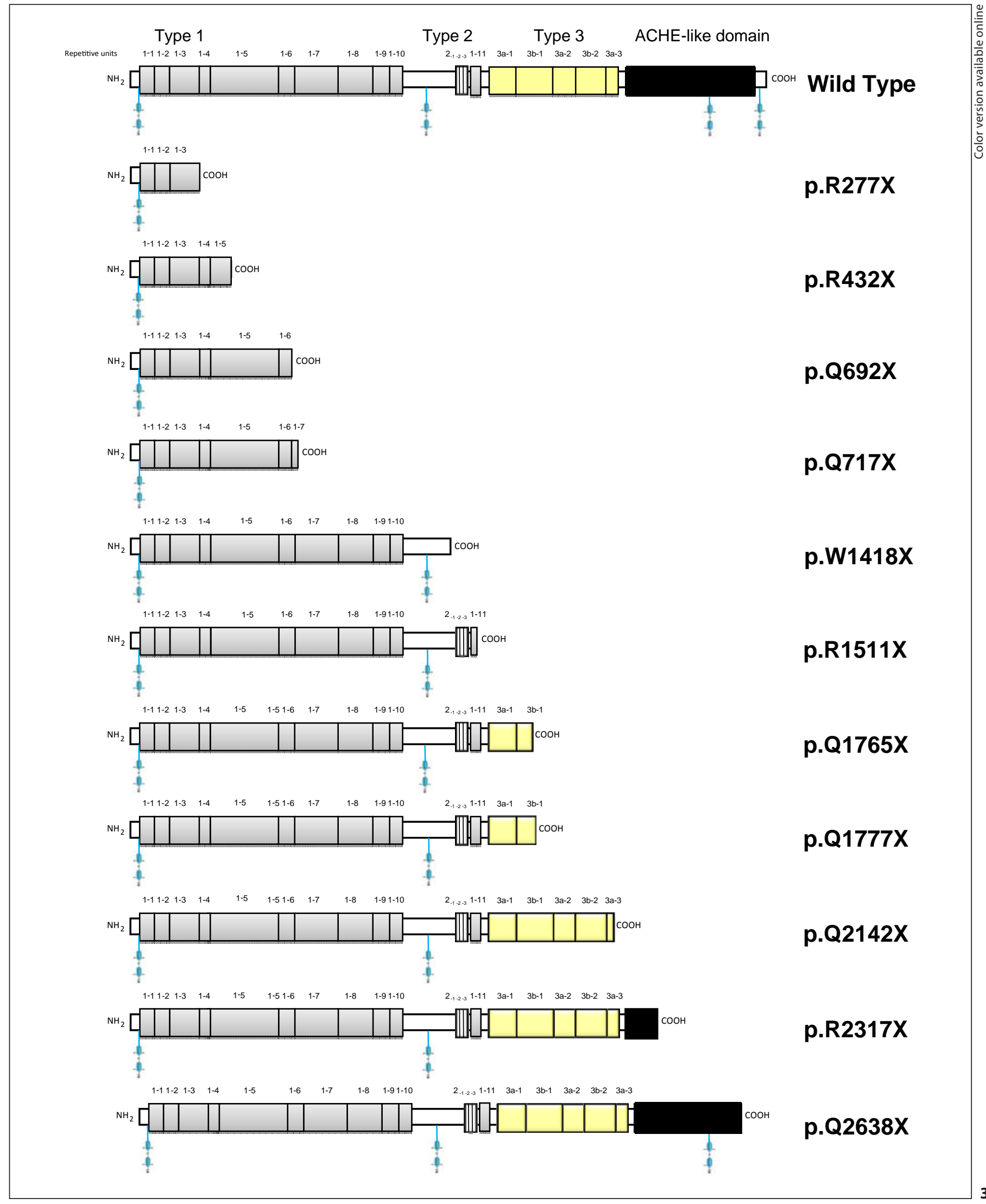


and hypothyroidism from Brazil, Argentina and France $[38,44,46,49,56]$ (fig. 3; table 1). The p.R1511X mutation is removed from the transcript by exon skipping using an alternative splicing $[38,46]$. The excision of mutated exon 22 in the pre-mRNA restores the reading frame allowing translation to reach the normal stop codon and results in an in-frame deletion of 57 amino acid residues [38]. In contrast, in vitro expression studies exclude an alternative splicing of exon 7 which could eliminate the p.R277X mutation and restores the normal reading frame $[41,55]$.

Truncated protein can be also caused by single nucleotide deletions $[30,43,54]$ and insertions [48] in the TG gene (table 1).

Biosynthesis of thyroid hormones is critically dependent of the native three-dimensional structure of TG and cysteines play an important role in this tertiary structure. Sequencing analysis of the TG gene revealed 9 missense mutations that involved wild-type cysteine residue: p.C164Y [48], p.C175G [30], p.C1058R [13, 30], p.C1245R $[13,30,40,50]$, p.C1588F [30], p.C1878Y [30, 47], p.C1977S $[13,30,40]$, p.C1987Y [30] and p.C2135Y [30] (table 1). The loss of cysteine residues can eliminate disulfide bonds and alter the normal conformational structure of the TG, consequently preventing the interaction of acceptor and donor hormonogenic sites.

Six missense mutations were reported in the ACHE homology domain: p.A2215D [48, 52, 53, 55], p.R2223H $[15,43,55]$, p.G2300D [30], p.R2317Q [30, 47], p.G2355V [30] and p.G2356R $[13,50]$ (table 1). Functional analysis suggests that the p.A2215D mutation results in retention of the TG protein inside the ER [53], as already observed in other missense mutations localized to the ACHE homology domain in the $\operatorname{cog} / \operatorname{cog}$ congenital goiter mouse (c.6848T $>$ C [p.L2263P]) [20] and the $r d w / r d w$ rat (c.6958G>C [p.G2300R]) [21, 22].

\section{Fetal Goiter and Prenatal Thyroid Hormone Treatment}

There are three types of thyroid deficiency states known to impact fetal development: isolated maternal hypothyroidism by autoimmune diseases, isolated fetal hypothyroidism by known or unknown thyroid function disorders and iodine deficiency combined with maternal and fetal hypothyroidism. The occurrence of fetal goiter may be a consequence of severe hormone synthesis dysfunction during prenatal life due to TG deficiency. This situation could be responsible for complications during pregnancy and delivery, such as hyperextension of the neck with bad presentation and complicating labor and delivery, tracheal compression with asphyxia and early neonatal death [59]. Antenatal diagnosis could be performed by fetal ultrasound looking for a goiter and by amniotic fluid or umbilical vein blood sampling assessing fetal serum thyroid function $[1,2]$. Fetal goiter can indicate hyperthyroidism or hypothyroidism. Therefore, it is necessary to determine the status of thyroid function. Fetal hypothyroidism may be prevented by intra-amniotic injections of L-thyroxine $[1,2,43,52,58]$. However, prenatal treatment of goitrous hypothyroidism may be considered controversial and the number of patients treated by intra-amniotic administration of L-thyroxine was too small to draw some clear conclusions on the benefits. Prenatal treatment varied widely in terms of $\mathrm{L}$-thyroxine dosage (150-800 $\mu \mathrm{g} /$ injection), number of injections (1-6), and frequency (1-4 weeks). Cordocentesis and intra-amniotic treatment carries a risk such as fetal bleeding, infection, fetal bradycardia, fetal death and premature labor.

The first patients with fetal goiter, hypothyroidism and a documented TG gene mutation were reported by Caron et al. [43]. A healthy mother evidenced during her two successive pregnancies the presence of a fetal goiter at 6 months of gestation by ultrasonographic studies, and umbilical-vein blood sampling showed severe fetal hypothyroidism. The fetus of the first pregnancy was treated by the intra-amniotic injection of $200 \mu \mathrm{g}$ L-thyroxine at the beginning and at the end of the 7 th month of gestation, whereas in the second pregnancy was treated with $500 \mu \mathrm{g}$ at 32 and 36 weeks. Later ultrasound evaluation showed clearly decrease of the goiter size in both fetuses and the woman had an uncomplicated, spontaneous vaginal delivery at 41 and 37 weeks of gestation, respectively. Cord blood analysis indicated low serum TG concentration [43]. The neonates presented no palpable goiter at birth, and they had normal clinical growth and cognitive development after thyroid hormone therapy. Genomic DNA sequencing identified the presence of compound heterozygous mutations of the TG gene: p.G362fsX382/ p.R2223H [43] (table 1).

A second patient with a large fetal goiter was identified by ultrasound in her mother at 26 weeks of gestation. At 29 weeks, fetal hypothyroidism was confirmed by cordocentesis [52]. Marked reduction in the goiter was noted 4 weeks after a single intra-amniotic injection of 400 mg L-thyroxine. Cord serum TSH, total $\mathrm{T}_{4}$, and free $\mathrm{T}_{4}$ were normal at birth and serum TG level was at the lower limit of detection [52]. Molecular analysis revealed g.IVS30+1G $>$ T homozygous mutation [52]. 
Recently, in a 27-year-old woman, a fetal goiter was diagnosed coincidentally by ultrasound at the 22nd week of gestation [58]. Percutaneous umbilical vein blood sampling under ultrasound guidance was performed at the 25 th week of gestation, showing important fetal hypothyroidism with high serum TSH and low free $\mathrm{T}_{4}$ levels. The fetus was treated by the intra-amniotic injection of 180 $\mu \mathrm{g}$ L-thyroxine at the end of the 27 th week, at the beginning of the 30th week and at the end of the 32nd week of gestation. The woman had a cesarean delivery at the 34 th week of gestation for fetal suffering. The neonate had a moderate asymmetric thyroid goiter with right predominance [58]. Sequence analysis of the TG gene revealed the presence of a compound heterozygous for p.R277X/ p.Q717X mutations [58].

More recently, a retrospective study of 12 prenatally treated fetuses showed decrease of thyroid size in 8 of 9 cases and intra-amniotic TSH values returned to normal in 4 cases and decreased in the remaining 2 cases [60]. However, at birth, all babies had hypothyroidism, indicating that the amniocentesis seems inadequate for monitoring fetal thyroid function.

Further studies are required to define the optimal gestational age to start intra-amniotic thyroxine therapy as well as the appropriate thyroid hormone dose and interval in order to improve prenatal thyroid hormone treatment of fetal goitrous hypothyroidism.

\section{Conclusion and Clinical Perspectives}

In the last decade, remarkable advances have been made in the understanding of the pathophysiology the TG deficiency and in the identification of the mutations.
New insights are provided by studies of the phenotypes and genotypes. However, several points on the development of this disease and the prevention remain to be elucidated. Little is known about the three-dimensional structure of this protein and there are no X-ray crystallographic data of any TG regions. Furthermore, the exact contribution of the TG mutations on the tertiary structure needs to be defined.

Prevention of congenital goiter is based on carrier identification, genetic counseling and prenatal diagnosis. The prevalence of a limited number of mutations in each population will facilitate greatly the molecular genetic testing. Prenatal diagnosis for pregnancies of increased risk is possible by analysis of DNA isolated from fetal cells obtained by means of amniocentesis or chorionic villi sampling. In the near future, preimplantation genetic diagnosis will be available for families in which the diseasecausing mutations have been identified.

Finally, new approaches including the use of gene chips, multiplex ligation-dependent probe amplification and new sequencing technology will eclipse traditional methods of detecting mutations and will allow to identify rapidly mutations in remote regions and to characterize large deletions in the TG gene.

\section{Acknowledgements}

C.E. Citterio is a research fellow of the Consejo Nacional de Investigaciones Científicas y Técnicas (CONICET). C.M.R. and H.M.T. are established investigators of the CONICET. This work was supported by grants from Universidad de Buenos Aires (B 078/2008 to H.M.T.) and CONICET (PIP 112-2000801-0054/2009 to C.M.R. and H.M.T.).

\section{References}

1 Park SM, Chatterjee VKK: Genetics of congenital hypothyroidism. J Med Genet 2005; 42:379-389.

2 Rastogi MV, La Franchi SH: Congenital hypothyroidism. Orphanet J Rare Dis 2010;5: 17.

3 Spitzweg C, Morris JC: Genetics and phenomics of hypothyroidism and goiter due to NIS mutations. Mol Cell Endocrinol 2010; 322:56-63.

4 Bizhanova A, Kopp P: Genetics and phenomics of Pendred syndrome. Mol Cell Endocrinol 2010;322:83-90.
5 Ris-Stalpers C, Bikker H: Genetics and phenomics of hypothyroidism and goiter due to TPO mutations. Mol Cell Endocrinol 2010; 322:38-43.

6 Grasberger H: Defects of thyroidal hydrogen peroxide generation in congenital hypothyroidism. Mol Cell Endocrinol 2010;322:99106.

7 Moreno JC, Visser TJ: Genetics and phenomics of hypothyroidism and goiter due to iodotyrosine deiodinase (DEHAL1) gene mutations. Mol Cell Endocrinol 2010;322:91-98.

8 Targovnik HM, Esperante SA, Rivolta CM: Genetics and phenomics of hypothyroidism and goiter due to thyroglobulin mutations. Mol Cell Endocrinol 2010;322:44-55.
9 Cavarzere P, Castanet M, Polak M, Raux-Demay MC, Cabrol S, Carel JC, Léger J, Czernichow P: Clinical description of infants with congenital hypothyroidism and iodide organification defects. Horm Res 2008;70: 240-248.

10 Corral J, Martín C, Pérez R, Sánchez I, Mories MT, San Millan JL, Miralles JM, González-Sarmiento R: Thyroglobulin gene point mutation associated with non-endemic simple goitre. Lancet 1993;341:462-464.

11 Pérez-Centeno C, González-Sarmiento R, Mories MT, Corrales JJ, Miralles-García JM: Thyroglobulin exon 10 gene point mutation in a patient with endemic goiter. Thyroid 1996;6:423-427. 
12 González-Sarmiento R, Corral J, Mories MT, Corrales JJ, Miguel-Velado E, Miralles-Garcia JM: Monoallelic deletion in the $5^{\prime}$ region of the thyroglobulin gene as a cause of sporadic nonendemic simple goiter. Thyroid 2001;11:789-793.

13 Hishinuma A, Fukata S, Kakudo K, Murata Y, Ieiri T: High incidence of thyroid cancer in long-standing goiters with thyroglobulin mutations. Thyroid 2005;15:1079-1084.

14 Alzahrani AS, Baitei EY, Zou M, Shi Y: Metastatic thyroid follicular carcinoma arising from congenital goiter due to a novel splice donor site mutation in the thyroglobulin gene. J Clin Endocrinol Metab 2006;91:740746.

15 Raef H, Al-Rijjal R, Al-Shehri S, Zou M, AlMana H, Baitei EY, Parhar RS, Al-Mohanna FA, Shi Y: Biallelic p. R2223H mutation in the thyroglobulin gene causes thyroglobulin retention and severe hypothyroidism with subsequent development of thyroid carcinoma. J Clin Endocrinol Metab 2010;95:10001006.

16 Tomer Y, Greenberg DA, Concepcion E, Ban Y, Davies TF: Thyroglobulin is a thyroidspecific gene for the familial autoimmune thyroid diseases. J Clin Endocrinol Metab 2002;87:404-407.

17 Ieiri T, Cochaux P, Targovnik HM, Suzuki M, Shimoda S-I, Perret J, Vassart G: A 3' splice site mutation in the thyroglobulin gene responsible for congenital goiter with hypothyroidism. J Clin Invest 1991;88:19011905.

18 Ricketts MH, Simons MJ, Parma J, Mercken L, Dong Q, Vassart G: A nonsense mutation causes hereditary goitre in the Afrikander cattle and unmasks alternative splicing of thyroglobulin transcripts. Proc Natl Acad Sci USA 1987;84:3181-3184.

19 Veenboer GJM, de Vijlder JJM: Molecular basis of the thyroglobulin synthesis defect in Dutch goats. Endocrinology 1993;132:377381.

20 Kim PS, Hossain SA, Park Y-N, Lee I, Yoo S-E, Arvan P: A single amino acid change in the acetylcholinesterase-like domain of thyroglobulin causes congenital goiter with hypothyroidism in the $\operatorname{cog} / \operatorname{cog}$ mouse: a model of human endoplasmic reticulum storage diseases. Proc Natl Acad Sci USA 1998;95: 9909-9913.

21 Hishinuma A, Furudate S-I, Masamichi O-I, Nagakubo N, Namatame T, Ieiri T: A novel missense mutation (G2320R) in thyroglobulin causes hypothyroidism in rdw rats. Endocrinology 2000;141:4050-4055.

22 Kim PS, Ding M, Menon S, Jing C-G, Cheng J-M, Miyamoto T, Li B, Furudate S-I, Agui T: A missense mutation G2320R in the thyroglobulin gene causes non-goitrous congenital primary hypothyroidism in the WIC-rdw rat. Mol Endocrinol 2000;14:1944-1953.
23 Mercken L, Simons MJ, Swillens S, Massaer M, Vassart G: Primary structure of bovine thyroglobulin deduced from the sequence of its 8431-base complementary DNA. Nature 1985;316:647-651.

24 Baas F, van Ommen G-JB, Bikker H, Arnberg AC, de Vijlder JJM: The human thyroglobulin gene is over $300 \mathrm{~kb}$ long and contains introns of up to $64 \mathrm{~kb}$. Nucleic Acids Res 1986;14:5171-5186.

25 Malthièry Y, Lissitzky S: Primary structure of human thyroglobulin deduced from the sequence of its 8448-base complementary DNA. Eur J Biochem 1987;165:491-498.

26 Mendive FM, Rivolta CM, Vassart G, Targovnik HM: Genomic organization of the 3' region of the human thyroglobulin gene. Thyroid 1999;9:903-912.

27 Moya CM, Mendive FM, Rivolta CM, Vassart G, Targovnik HM: Genomic organization of the $5^{\prime}$ region of the human thyroglobulin gene. Eur J Endocrinol 2000;143:789798.

28 Mendive FM, Rivolta CM, Moya CM, Vassart G, Targovnik HM: Genomic organization of the human thyroglobulin gene. The complete intron-exon structure. Eur J Endocrinol 2001;145:485-496.

29 Van de Graaf SAR, Ris-Stalpers C, Pauws E, Mendive FM, Targovnik HM, de Vijlder JJM: Up to date with human thyroglobulin. J Endocrinol 2001;170:307-321.

30 Hishinuma A, Fukata S, Nishiyama S, Nishi Y, Oh-Ishi M, Murata Y, Ohyama Y, Matsuura N, Kasai K, Harada S, Kitanaka S, Takamatsu J, Kiwaki K, Ohye H, Uruno T, Tomoda C, Tajima T, Kuma K, Miyauchi A, Ieiri T: Haplotype analysis reveals founder effects of thyroglobulin gene mutations C1058R and C1977S in Japan. J Clin Endocrinol Metab 2006;91:3100-3104.

31 Swillens S, Ludgate M, Mercken L, Dumont JE, Vassart G: Analysis of sequence and structure homologies between thyroglobulin and acetylcholinesterase: possible functional and clinical significance. Biochem Biophys Res Commun 1986;137:142-148.

32 Novinec M, Kordiš D, Turk V, Lenarčič B: Diversity and evolution of the thyroglobulin type-1 domain superfamily. Mol Biol Evol 2006;23:744-755.

33 Park YN, Arvan P: The acetylcholinesterase homology region is essential for normal conformational maturation and secretion of thyroglobulin. J Biol Chem 2004;279:1708517089

34 Lee J, Wang X, Di Jeso B, Arvan P: The cholinesterase-like domain, essential in thyroglobulin trafficking for thyroid hormone synthesis, is required for protein dimerization. J Biol Chem 2009;284:12752-12761.

35 Lee J, Di Jeso B, Arvan P: The cholinesteraselike domain of thyroglobulin functions as an intramolecular chaperone. J Clin Invest 2008;118:2950-2958.
36 Lamas L, Anderson PC, Fox JW, Dunn JT: Consensus sequences for early iodination and hormonogenesis in human thyroglobulin. J Biol Chem 1989;264:13541-13545.

37 Dunn AD, Corsi CM, Myers HE, Dunn JT: Tyrosine 130 is an important outer ring donor for thyroxine formation in thyroglobulin. J Biol Chem 1998;273:25223-25229.

38 Targovnik HM, Medeiros-Neto G, Varela V, Cochaux P, Wajchenberg BL, Vassart G: A nonsense mutation causes human hereditary congenital goiter with preferential production of a 171-nucleotide-deleted thyroglobulin ribonucleic acid messenger. J Clin Endocrinol Metab 1993;77:210-215.

39 Targovnik H, Vono J, Billerbeck AEC, Cerrone GE, Varela V, Mendive F, Wajchenberg BL, Medeiros-Neto G: A 138-nucleotide deletion in the thyroglobulin ribonucleic acid messenger in a congenital goiter with defective thyroglobulin synthesis. J Clin Endocrinol Metab 1995;80:3356-3360.

40 Hishinuma A, Takamatsu J, Ohyama Y, Yokozawa T, Kanno Y, Kuma K, Yoshida S, Matsuura N, Ieiri T: Two novel cysteine substitutions (C1263R and C1995S) of thyroglobulin cause a defect in intracellular transport of thyroglobulin in patients with congenital goiter and the variant type of adenomatous goiter. J Clin Endocrinol Metab 1999;84:1438-1444.

41 Van de Graaf SAR, Ris-Stalpers C, Veenboer GJM, Cammenga M, Santos C, Targovnik HM, de Vijlder JJM, Medeiros-Neto G: A premature stop codon in thyroglobulin mRNA results in familial goiter and moderate hypothyroidism. J Clin Endocrinol Metab 1999;84:2537-2542.

42 Targovnik HM, Rivolta CM, Mendive FM, Moya CM, Medeiros-Neto G: Congenital goiter with hypothyroidism caused by a $5^{\prime}$ splice site mutation in the thyroglobulin gene. Thyroid 2001;11:685-690.

43 Caron P, Moya CM, Malet D, Gutnisky VJ, Chabardes B, Rivolta CM, Targovnik HM: Compound heterozygous mutations in the thyroglobulin gene (1143delC and $6725 \mathrm{G}>\mathrm{A}[\mathrm{R} 2223 \mathrm{H}]$ ) resulting in fetal goitrous hypothyroidism. J Clin Endocrinol Metab 2003;88:3546-3553.

44 Gutnisky VJ, Moya CM, Rivolta CM, Domené S, Varela V, Toniolo JV, MedeirosNeto G, Targovnik HM: Two distinct compound heterozygous constellation (R277X/ IVS34-1G>C and R277X/R1511X) in the thyroglobulin (TG) gene in affected individuals of a Brazilian kindred with congenital goiter and defective TG synthesis. J Clin Endocrinol Metab 2004;89:646-657. 
45 Rivolta CM, Moya CM, Gutnisky VJ, Varela V, Miralles-García JM, González-Sarmiento R, Targovnik HM: A new case of congenital goiter with hypothyroidism due to a homozygous p.R277X mutation in the exon 7 of the thyroglobulin gene: a mutational hot spot could explain the recurrence of this mutation. J Clin Endocrinol Metab 2005;90:37663770 .

46 Mendive FM, Rivolta CM, GonzálezSarmiento R, Medeiros-Neto G, Targovnik HM: Nonsense-mediated alternative splicing of the human thyroglobulin gene. Mol Diagn 2005;9:143-149.

47 Kitanaka S, Takeda A, Sato U, Miki Y, Hishinuma A, Ieiri T, Igarashi T: A novel compound heterozygous mutation in the thyroglobulin gene resulting in congenital goitrous hypothyroidism with high serum triiodothyronine levels. J Hum Genet 2006; 51:379-382.

48 Caputo M, Rivolta CM, Esperante SA, Gruñeiro-Papendieck L, Chiesa A, Pellizas CG, González-Sarmiento R, Targovnik HM: Congenital hypothyroidism with goitre caused by new mutations in the thyroglobulin gene. Clin Endocrinol (Oxf) 2007;67:351357.

49 Caputo M, Rivolta CM, Gutnisky VJ, Gruñeiro-Papendieck L, Chiesa Medeiros-Neto G, González-Sarmiento R, Targovnik HM: Recurrence of the p.R277X/p.R1511X compound heterozygous mutation in the thyroglobulin gene in unrelated families with congenital goiter and hypothyroidism: haplotype analysis using intragenic thyroglobulin polymorphisms. J Endocrinol 2007;195:167177.
50 Kanou Y, Hishinuma A, Tsunekawa K, Seki K, Mizuno Y, Fujisawa H, Imai T, Miura Y, Nagasaka T, Yamada C, Ieiri T, Murakami M, Murata Y: Thyroglobulin gene mutations producing defective intracellular transport of thyroglobulin are associated with increased thyroidal type- 2 iodothyronine deiodinase activity. J Clin Endocrinol Metab 2007;92:1451-1457.

51 Kim PS, Lee J, Jongsamak P, Menon S, Li B, Hossain SA, Bae J-H, Panijpan B, Arvan P: Defective protein folding and intracellular retention of thyroglobulin-R19K mutant as a cause of human congenital goiter. Mol Endocrinol 2008;22:477-484.

52 Pardo V, Rubio IG, Knobel M, AguiarOliveira MH, Santos MM, Gomes SA, Oliveira CR, Targovnik HM, Medeiros-Neto G: Phenotypic variation among four family members with congenital hypothyroidism caused by two distinct thyroglobulin gene mutations. Thyroid 2008;18:783-786.

53 Pardo V, Vono-Toniolo J, Rubio IG, Knobel M, Possato RF, Targovnik HM, Kopp P, Medeiros-Neto G: The p.A2215D thyroglobulin gene mutation leads to deficient synthesis and secretion of the mutated protein and congenital hypothyroidism with wide phenotype variation. J Clin Endocrinol Metab 2009;94:2938-2944.

54 Niu DM, Hsu JH, Chong KW, Huang CH, Lu YH, Kao CH, Yu HC, Lo MY, Jap TS: Six new mutations of the thyroglobulin gene discovered in Taiwanese children presenting with thyroid dyshormonogenesis. J Clin Endocrinol Metab 2009;94:5045-5052.

55 Machiavelli GA, Caputo M, Rivolta CM, Olcese MC, Gruñeiro-Papendieck L, Chiesa A, González-Sarmiento R, Targovnik HM: Molecular analysis of congenital goiters with hypothyroidism caused by defective thyroglobulin synthesis. Identification of a novel c.7006C $>$ T [p.R2317X] mutation and expression of minigenes containing nonsense mutations in exon 7. Clin Endocrinol (Oxf) 2010;72:112-121.
56 Targovnik HM, Souchon PF, Machiavelli GA, Salmon-Musial AS, Mauran PL, Sulmont V, Doco-Fenzy M, Rivolta CM: Congenital goitre with hypothyroidism caused by a novel compound heterozygous mutations in the thyroglobulin gene. Clin Endocrinol (Oxf) 2010:72:716-718.

57 Peteiro-Gonzalez D, Lee J, Rodriguez-Fon$\tan$ J, Castro-Piedras I, Cameselle-Teijeiro J, Beiras A, Bravo SB, Alvarez CV, Hardy DM, Targovnik HM, Arvan P, Lado-Abeal J: New insights into thyroglobulin pathophysiology revealed by the study of a family with congenital goiter. J Clin Endocrinol Metab 2010; 95:3522-3526.

58 Citterio CE, Coutant R, Rouleau S, Miralles García JM, Gonzalez-Sarmiento R, Rivolta CM, Targovnik HM: A new compound heterozygous for c. $886 \mathrm{C}>\mathrm{T} / \mathrm{c} .2206 \mathrm{C}>\mathrm{T}$ [p.R277X/p.Q717X] mutations in the thyroglobulin gene as a cause of foetal goitrous hypothyroidism. Clin Endocrinol (Oxf) 2011. DOI: 10.1111/j.1365-2265.2010.03932.x.

59 Abuhamad AZ, Fisher DA, Worsof SL, Slotnick RN, Pyle PG, Wu SY, Evans AT: Antenatal diagnosis and treatment of fetal goitrous hypothyroidism: case report and review of the literature. Ultrasound Obstet Gynecol 1995;6:368-371.

60 Ribault V, Castanet M, Bertrand AM, Guibourdenche J, Vuillard E, Luton D, Polak M, French Fetal Goiter Study Group: Experience with intra-amniotic thyroxine treatment in nonimmune fetal goitrous hypothyroidism in 12 cases. J Clin Endocrinol Metab 2009;94:3731-3739. 